\title{
INDIGENOUS STUDENTS’ PERCEPTIONS OF FACTORS CONTRIBUTING TO SUCCESSFUL LAW STUDIES
}

\author{
CAROLYN PENFOLD*
}

\section{INTRODUCTION}

While the under-representation of Aborigines and Torres Strait Islanders in formal education is apparent in pre-school and in the compulsory years of schooling, it becomes more marked at the higher levels of education, and by university level the under-representation is extreme. ${ }^{1}$ Studies have frequently looked at the needs of Aboriginal and Torres Strait Islander students and identified difficulties which these students face in the formal academic system. ${ }^{2}$ Lack of financial support, schooling background, pressure from family and community, health problems, inappropriate curricula, identity crises and negative stereotyping have all been identified as contributing to the poor rates of Indigenous participation and success in formal education. $^{3}$

As a result, Indigenous Australians ${ }^{4}$ are under-represented in all professions, including law. ${ }^{5}$ Access to studies has become less a barrier since the introduction of discretionary admissions schemes to most Australian universities, but what Indigenous students experience while studying law clearly militates against them completing degrees. While the number of Indigenous law graduates has greatly increased in recent years, ${ }^{6}$ attrition is still of concern. ${ }^{7}$ Law schools continue therefore to search for ways to attract, retain and graduate Indigenous students. This study is a step in that process.

\section{THIS STUDY}

Non Indigenous students attend law schools expected and expecting to succeed, while for Indigenous students failure or discontinuation of studies is still considered normal. The need to study factors contributing to Indigenous student success itself suggests the inappropriateness of mainstream law schools for many Indigenous students. As a result it has been argued that improving Indigenous education may require specifically Indigenous institutional structures, teaching methods and curricula. ${ }^{8}$ This larger question of what kind of education is really appropriate to Indigenous people remains controversial.

However, Indigenous Australians wishing to study law currently need to do so in non-Indigenous mainstream institutions. This study aimed therefore to identify factors which assist Indigenous students to succeed in those institutions, and to identify what law schools may do to encourage that success.

Indigenous students and recent graduates of UNSW Law Faculty were invited to take part in the study. Nineteen volunteers were then asked by an Aboriginal interviewer what they believe contributes or contributed to the completion of their law studies. Interviews were informal and unstructured. They were taped and fully transcribed. All participants had progressed beyond the first stage of their studies, and five were graduates/graduands.

The study was not intended to test any particular hypothesis, but rather to produce a picture of positive experiences which contribute to Indigenous students completing law degrees. A qualitative analysis of transcripts identified factors most commonly and most passionately believed by students to contribute to the completion of law studies. ${ }^{9}$ Categories were not pre-determined but emerged through analysis of the transcripts as a whole. Contributions which were significant to many students but which also drew some negative comments are discussed in the text. Factors about which there was ambivalence, factors making 
insignificant contributions to success, and personal or other factors identified by few students only are not discussed.

All participants were invited to comment on a draft of this paper prior to publication, and their comments have been taken into account in the final draft.

\section{FACTORS MILITATING AGAINST INDIGENOUS STUDENTS COMPLETING LAW DEGREES}

While interviews conducted for the present study asked students only about success, many students referred to the difficulties they faced in order to explain the positive factors which helped them. All the difficulties identified in previous studies ${ }^{10}$ were experienced to some degree by Indigenous law students participating in the current study. Student accounts best illustrate these difficulties, which include experiences of alienation, lack of confidence, and language barriers:

The language is a problem. They're using words that even an educated blackfella hasn't heard. And assumed knowledge is a problem with the lecturers. They assume you know the words they're using ... but they're not ours. And I spent my first year here with a dictionary. Every word they said, I had a list at the back of my book and I'd add to it, go home, check out what it meant. And then just every night go over the list to try and remember what they were. I just didn't want to appear dumb. ${ }^{11}$

Even just in presentations and things you do in class, you feel that everyone else is using this amazing language and I'm not making myself clear and they're just all sitting there, thinking ...' why aren't you using the same sort of words we are?'

... A lot of Aboriginal students constantly question why we're here and how we can compete against a lot of these kids.

I guess I don’t see any sort of Koori focus, I certainly know I don’t fit into the activities that I see that happen.

You could understand somebody starting for the first time just being so intimidated by the whole thing. If I can't cope with enrolment, how can I cope with going to a class? I had an aunty enrolled here, and she never came for that reason.

[respondent and another Aboriginal student] ... Used to cling to each other, walking around corridors in this place, wasn't confident to go into any place for a cup of coffee or to eat food here, wasn't confident to hang around. The library was a nightmare, absolute nightmare because we couldn't understand how to use it and you were constantly worried that someone was gonna find out how dumb you were.

Many of these experiences are common to Indigenous students in other disciplines also, although it is likely that the lack of confidence is far more pronounced in law schools where students are truly the state's top academic performers. A Tertiary Entrance Ranking (TER) of 98.55 was required for entry to law at UNSW in 1995 and these TER rankings of non-Indigenous students were referred to repeatedly in interviews.

In addition to these difficulties, it appears that efforts made to introduce relevant and appropriate material to the Law School curriculum generally, and especially to first year subjects, have not reduced the anxiety for Indigenous students. While this anxiety remains throughout the degree for some students, extracts relating to first year clearly illustrate the complexity of the issues involved. These include the pressure to be expert about Indigenous issues and of not fitting the stereotypes of white students and teachers, the need to correct others' misunderstandings, and the emotional entanglement with the material presented: ${ }^{12}$

(What) ... I found really hard was the first subject you get taught when you come into the Law School ... Aboriginal Law, history of law, terra nullius, all that sort of stuff ... And if it's not handled sensitively it can be very confronting for an Aboriginal student. And that's the first thing they come into - they struggle to get hold of what's going on in two weeks - bang! - they're talking about YOU. Your people, your culture. Right? And it may not be the way you want it talked about or thought about, or handled.

One that is vivid in my memory is my first class ... And we were going through ... I think it was the history of white settlement and how ... hundreds of Aboriginal people were murdered etc. And it was a video. And a lot of people were affected by that visual image, you know, and they started crying, and the video was stopped and the comments from ... from the other students in that class was "My God, I'm ashamed to be white". And then they started talking on. And then someone raised the issue of “well, but, the thing is we don't see any Aboriginal people here on campus. 
Right?” So, I'm the only one sitting in the class and I just put my hand up and said "well, there's one sitting over here”. And it was like, they were shocked to see an Aboriginal person sitting in that class, who wasn't black as the ace of spades, who wasn't carrying a spear and wasn't wearing a loincloth ...

Clearly, Indigenous law students still face the enormous difficulties common to other Indigenous students. These difficulties may be further exacerbated for law students by the discipline itself, its basis in the doctrine of terra nullius, and the role the legal system has played in the denial of Indigenous rights. Given this, the continuing high attrition rates are understandable and it is perhaps more surprising that Indigenous students do progress through their studies to complete law degrees. The remainder of this paper looks at those factors which students believe assist them in this progress.

\section{CONTRIBUTORS TO SUCCESS}

The Indigenous students interviewed for this study were able to identify many factors, both within the Law School and outside it, which contribute to completing law studies. An analysis of responses found that students believed their own motivation and determination to be the most significant factor involved in completing their courses. Other factors with important positive impact were:

- the opportunity to network with other Indigenous students,

- role models,

- the supportive atmosphere of the Law Faculty,

- relevant and appropriate curricula,

- the support scheme for Indigenous students within the Law Faculty,

- the Aboriginal Tutorial Assistance Scheme,

- cadetships and professional support, and

- the availability of exchange programs.

While successfully completing law studies is clearly the achievement of students themselves, it is heartening to learn that much of what influences or encourages Indigenous student success is within the power of the university and its staff. It is clear from student responses that changes in university policy, in systems and environment, in staff attitudes and behaviour, and in the resources provided really can make a difference to the likelihood of Indigenous students completing law degrees. Although many factors identified as contributing to success overlap, it is convenient to discuss each of these factors individually.

\section{Student Motivation and Determination}

The students interviewed all displayed an overwhelming personal determination to complete law degrees. The words of many suggest that nothing and no-one could stop them from fulfilling this aim. Although the students' long term ambitions varied enormously, all displayed incredible personal motivation. Students' words best illustrate this determination:

Never once have I thought I'd throw it in. I've wanted to do (law) for so many years. I always wanted to do law. I couldn't bear to drop out and I wouldn't.

This is something that I've got to prove to myself that I can actually do.

I've never been a quitter. I've had a policy in life that if you start something you finish it off and to your benefit. You don't leave until you've done that otherwise you look back with regrets later on. I don't think it's the actual law that's kept me here, I hate it. I don't think I'll ever go into law.

I really wanted it so badly — and that made a big difference.

I keep pushing myself. I'm not a quitter, and at times I just feel like "let's go bash your head against a brick wall" and that's what it feels like, but I don't give up.

I will finish it, even if it takes me 20 years. I'm not going to drop out.

I don't for the life of me know why, but I've just been so determined to get a law degree all my life, that there's no way I'm going to quit until I've got it.

Although student motivation and determination are personal factors, universities are in a position both to 
use and to influence this. Firstly it would be useful for selection committees to give weight to any available evidence of student motivation. While this must be coupled with ability and academic skill, the failure and attrition rates of Indigenous students and the many factors inhibiting them from completing law degrees suggest that those without this hunger for completion will not survive.

Secondly, universities must nurture the student's own drive by providing an environment which strengthens a student's motivation to complete, as even the strongest motivation and determination can be lost in a discouraging environment. Universities must recognise that they do have influence over students retaining or losing their initial motivation. The personal resources of the Indigenous students interviewed were clearly bolstered by many factors within the university and a discussion of these follows. If these factors contributing to student completion can be maintained or even extended, student motivation and determination is likely to remain high.

\section{Indigenous Students and Friends, and the Influence of the Aboriginal Student Centre}

The availability of a centre for Indigenous students, and the support of other Indigenous students are so closely linked that they will be discussed together. It is clear from student responses that for them the most significant role of a Centre for Indigenous students is that of facilitating student networks, and that the availability of resources such as computers and study rooms were of secondary importance. ${ }^{13}$ The support offered generally by Indigenous students to one another was of exceptional benefit in helping them to complete degrees. This is particularly so as many students found the Law School and law studies a threat to the retention of their own culture, ${ }^{14}$ and felt out of place in the university environment. Networking with other Indigenous students helped to generate a feeling of belonging, and brought together students who understood and shared one another's anxieties:

(At the Aboriginal Student Centre) there'd be somebody there just to talk to you, or listen to your qualms and perhaps share them as well, and friendship, and the fact that when you went there you didn't feel like you were alone because everybody else was in the same boat as you.

... Just to sit down and talk to other students who have got similar problems and similar hassles and think, "Oh good, I'm not alone."

... for me, I suppose, the greatest resource is to network with other Koori students, and to sit down and talk to them and find out what they're hassling with and what they're struggling with, and realise I'm not the only one that could be struggling with this ...

Students may need the support of other Indigenous students to enable them to take part in the activities available at the university:

I'm not going to make shame if there's not going to be anyone else to make shame with ...

Having other Indigenous students in the classes made a huge amount of difference to the students, who often found being in a class of non-Indigenous students extremely isolating:

I think I'd quite like to have somebody else in a class even just to sit around and talk to 'cos it's different having Kooris there. There are some really good people in my classes and they've been quite helpful and supportive, but it's just different, having Kooris there.

There’s nothing more isolating than going into a class and being the only Aboriginal student there.

The benefit of the experience of later year Aboriginal students and graduates is well recognised by the students. As there are only 30 to 40 Indigenous law graduates in Australia, it is unlikely that students will have friends or family who have successfully studied law. Unfortunately, it is more likely that the student will know an Indigenous person who has attempted but never completed law studies. While students may have non-Indigenous friends who are studying or have completed their studies, responses clearly illustrate their need for the support of Indigenous people who have studied law successfully. A centre for Indigenous students is significant in the opportunity it affords for mixing with such experienced people:

You get a student's perspective on something. Someone that's only a year or two above you saying “Oh, I liked this course, it helped me a lot, I had difficulties in this, and if you need any help, come and see me”. 'Cos they've gone through it, and they can tell you what the particular lecturer you have, whether he's a good lecturer or whether you might have problems with them, being Aboriginal ... 
The students who rely on the experience of others recognise also their own responsibilities to provide that support as they become more senior themselves:

When I first started off there were only a few Koori students ahead of me, and I got a lot of help from them, and just seeing how far they've gotten, and then as each year passed, they were getting more and more young Koori students coming in behind me, and I kind of took the place of those older students to me, I became like that to the newer students, and that was really good, that was a good incentive to keep going.

I'd like to think I could give something back, even just talking to people, being there or even leaving my number for people who wanted to talk to me or ask me "what's happening, does it get any better or does it get more difficult?" You hear someone else saying (I'm going to fail), and you think "My God, that sounds like me two years ago," and you say to them "look, it'll pass',... And it does pass.

The need for and the benefit of the support of other Aboriginal students was felt especially strongly in the first year of university:

In first year it was good because I had some encouragement. Just a few of the other students, some of the older students said, “Oh, look, you'll get through it, don't worry about Torts” 'cos it was fairly daunting, and a lot of the time you're thrown into a class and you're thinking "My God, everyone else has got 99 or 100 TER or something and "how am I going to cope with this", and ... just talking to some of the students and seeing other students who are in higher years, and there were people graduating, was a big help, so that you knew that ... it was possible and that they'd done it, they'd stuck it out.

(re first year camp) ... I couldn't — I didn't have the strength to do it for a whole weekend by myself ... I had no idea. If I'd known that ... there'd be other Kooris, then I might have gone.

It was clear that many of the benefits of the Student Centre were intertwined, with students using the centre for academic support, personal support, socialising and more:

I just think we're so lucky here. To have the people we've got here. To have a Student Centre ... Whenever a problem comes up, whether it be a problem with College, with money, or whether it's an academic problem, or something like that, there's always somebody you can talk to about it. You can get help. It's just so great. And also like socially - like some place where you can feel at home. And especially when you have graduates and older students coming around all the time and you can talk to them.

... Having all the law students together and having that support, that network, knowing that you swap notes, you give notes to other people, you share books ... it's really good and I think that should be encouraged even more.

It's a meeting point, it's a facility that provides the opportunity for Indigenous students to meet ... I guess provide relief from battle, relief from the rush ... it provides the opportunity of rapport between students.

Unfortunately, some Indigenous students felt unable to take the benefit of the support offered through the Centre and by other students, due to pressures relating to identity issues:

I've had one run-in with one student, another Koori student, who doesn't like me ... I don't think she thinks I'm black enough.

I feel like, because I'm very white and I just think the Centre would think ... what's this whitey using all our resources for? ... I just feel very self-conscious about being so white and so I don't ... go over to the community places on campus ... I stick to myself.

As discussed above, Indigenous students often feel under pressure in classes because they don't fit others' stereotypes of what Aborigines look like. Unfortunately some feel that pressure even with other Indigenous students. This may be redressed somewhat if more care is taken early on in the process of special admissions. Introductory programs for all Indigenous students may help them to feel more comfortable with their own identities, and with those of others. The fairskinned student then would not only gain the support of other Indigenous students, but his or her very presence as part of the program would itself lend support to other fairskinned students. ${ }^{15}$

\section{Role Models}

Indigenous students rarely see or hear of Indigenous lawyers. They are unlikely to have lawyers as family. They may know people who have attempted to study law and failed, or who have failed at other tertiary education. Coupled with the fact that few, if any, Indigenous law students have achieved academically in secondary education like their law school counterparts, it can be difficult and extremely 
daunting for Indigenous people to take on law studies. Student responses show the overwhelming benefit of having role models who can assure students that successful completion of the course is possible for Indigenous people. The few high profile role models were mentioned repeatedly:

Probably the main role models that you see ... is sort of on the telly and people, for example, Noel Pearson and Pat O'Shane, just blackfellas with law degrees that you see up there achieving positive change, or at least attempting to.

I'd been interested in law ever since I was a kid, and never thought I'd have the brains to do it ... and then having worked in District Court and seen Pat O'Shane and talked to Pat, it gave me the confidence "well maybe I can do it" ... having actually been in her court for work, and seeing her operate, I think, "well, if she can do it, I can ..."

Because so few Indigenous people have graduated from law schools, the most exalted role models may themselves still be students or very recent graduates:

People like (named students) and other Aboriginal graduates, people who I can see have made it, and others who've made it this far. To me they're just amazing and I hear them rattling on about (what) they're doing and it's just full on. Just to see that others have made it through and ... having their knowledge of what it's like coming through because they've had five years' experience ... They've been through it before and so it's someone you can talk to about what it's like. But I think just the fact that they have made it is what's inspiring to me.

(named student) ... you're seeing somebody who's a bit older than me, thank God, who's completing- who's getting there. And she may have failed a couple of subjects but she doesn't let it get her down, she just keeps on slogging away, and it makes you realise you can get through.

Some of the Indigenous students see non-Indigenous class teachers as role models:

From what I hear (named teacher) seems to have an affinity with Aboriginal students. And those that have done his subjects seem to speak very highly of him. I think if he had the time to even visit the Centre occasionally, I think he would probably be an excellent role model.

One of my teachers ... She has really inspired me ... someone who's really, really interested in you, someone who wants you to do well, and because I'm still uncertain of where I want to go when I've finished my law degree teaching is one area that I'm thinking of going into — and so she's ... become a real role model for me.

Q Do you have any role models within the Law School?

A $\quad$... Yeah, the lecturers themselves.

Most students recognised that the dearth of Indigenous role models meant their own progress through the law degree elevated them to the position of role model for other students. They felt strongly the responsibility this carried with it, as well as the opportunities it gave them to improve things:

Students here today can change people's attitudes and beliefs about Aboriginal people. I hope to be part of changing those attitudes in some way. And if it means just completing my degree, and just letting people know that there are people, Aboriginal people who have law degrees ... then I think I'd be more than happy.

... When I do complete it I guess I can be a role model for some other young Aboriginal, Torres Strait Islander kids

In the past there hasn't been that many role models, so ... I see myself as being one in the forefront, I guess.

There is no doubt about the importance of appropriate role models to Indigenous students. The small number of graduates need not be entirely problematic however, as it is clear that in some cases students incorporate non-Indigenous teachers and others into their role modeling. The dearth of Indigenous lawyers will hopefully eventually be overcome, but in the meantime it may be worth putting into place other structures to allow Indigenous students the necessary contact with appropriate models.

Many students suggest that past graduates should continue to have input into Indigenous education programs, and at least at UNSW more recent graduates do seem to continue to be involved. Although a formal mentoring scheme may be of great benefit to undergraduates, ${ }^{16}$ in the past students who have been willing to be involved in community and support activities have often found themselves struggling with their own studies and other commitments. With so few completed and senior students there is a real danger that those willing to be involved may become overburdened. It may be more useful to encourage these prospective role models to take part in informal activities which allow them to lend support without the likelihood of over-commitment. 
Law teachers also have a role to play in the encouragement of Indigenous students. Teachers are in a good position to lend this kind of support to students without becoming over-committed or inappropriately committed. It is necessary first, however, to ensure that teachers are aware of the lack of Indigenous role models, and of how important the teacher may be in assisting students to achieve their aspirations.

\section{Teachers, and the Law School Atmosphere}

Individual teachers and the Law Faculty as a whole were seen as important contributors to the completion of degrees. The behaviour and attitudes of teachers generated a comfortable atmosphere within the School, and greatly encouraged Indigenous students.

\section{Individual Teachers}

Most students reported very positive experiences with individual teachers and were happy to recount particular examples. Interestingly, many of these incidents related to seemingly trivial occurrences, but for the students they resulted in an overall perception of helpfulness and support. The positive experiences with individual teachers were mirrored by students' feelings about the Faculty as a whole. Teachers were highly praised by students for the encouragement given:

... They have that individual interest in students, I really find that. And from talking to the students I've met at university I think they all feel the same ... The lecturers are special in this university, ... they have that individual interest ... caring.

... Teachers, everything, everyone's sort of organised around helping you to get through, this is very positively based on helping you get through, not ... putting as many obstacles in your way as they can.

They look at every student, Aboriginal or not, in terms of "how can I help them pass this course?"

\section{The Law School Atmosphere}

Students found the atmosphere of the Faculty to be one of support and encouragement. While some reported experiences of alienation and intimidation these were largely tempered by a genuine desire within the Faculty that they succeed. Although some students had less encouraging experiences with individual teachers none of the students interviewed felt other than supported by the Faculty generally. Students' words illustrate how strongly this was felt:

The whole Law Faculty is behind you. They're wanting you to come, they're wanting to help you and the whole support I think is what's so encouraging. And that makes me feel comfortable here. Never once have I found it intimidating.

If you don't want to be kept there, you won't be. Everything is there for you to excel. And excel in terms of success. In terms of obtain that degree. I think that the systems are there, everything is there to help you.

In the Law School itself, they did tend to have a good attitude toward Indigenous peoples generally... . you've got your exceptions always, but in general they put Indigenous peoples in a positive light ... it's encouraging when that happens and it sort of makes you want to go further and push yourself a bit and, just be one of those Indigenous people in the Law School that do get through.

Written policies of support for Indigenous students may heighten a faculty's awareness of the difficulties which these students face. UNSW Law Faculty's Corporate Plan includes reference to improving conditions for Indigenous students, ${ }^{17}$ and claims as distinctive "an emphasis on social justice as an underpinning value in the processes and programs of the Faculty. ${ }^{18}$ However, the perception of support within the Faculty is generated most powerfully by the behaviour of individuals, and while written policies may encourage that behaviour, an honest desire amongst staff that students succeed will more directly benefit students.

Introducing Indigenous students to staff early in their studies may help to convey to them the faculty's support and encouragement, rather than leaving students to discover that support when they have problems. However, Indigenous students often do not wish to be identified to teachers, particularly when they are just beginning in a law school. An informal gathering with only a few staff may be a start. Alternatively, key staff could meet new students through an Indigenous program on campus, meeting students on their own 
territory and showing an interest in making them feel welcome and comfortable.

\section{Other Students}

Another aspect of the Law School atmosphere involves relations with non-Indigenous students. Unfortunately, while students felt so supported by Faculty staff, a few felt less comfortable with other students. Most students did not mention this difficulty, but for those who did the alienation continued to be extreme.

I sit in class with kids, white kids whose parents are doctors, lawyers, accountants, kind of thing and they have got very upper middle class background, some filthy rich, and just talking to them, it's obvious that from day one, basically, they are inculcated with an attitude ...

It's more the students than anything else, very middle class ... I have a problem with a lot of the students, they just seem so middle class ... I don't know, just so influenced by what a lawyer is expected to be that they just seem to be being bred for those horrible lawyer jokes.

It's pretty conservative. You get a lot of pretentious people - from a black perspective - that come from really really nice homes, really really wealthy families, have never had to work a day in their lives to get anything, don't understand that there's a lot of students there that basically support themselves ... it makes it hard when you come in to Uni one day and you've just been flat out saving to get your rent paid and you've got ... law students and they're talking about how they went to the snow on the weekend, and how Mummy and Daddy paid for the trip down and, "Oh, I stayed in this resort and that resort" ... you know, and you've come in and you're just flat out saving your rent, getting that together and buying a feed for the day. And it's hard sometimes ... it sort of puts a lot of strain on you.

It is unfortunate that some Indigenous students feel so alienated from non-Indigenous students. This may be another area where the experience of past students could be beneficial; some students found that they had a lot more support at university once they broadened their group of friends to include nonIndigenous students. It should be remembered however that not all suggest difficulties with non- Indigenous students:

It's basically pretty friendly, I mean you still get - there is some racism around, but not a lot. But a lot of it's ignorance, more than anything else, and kids will come up — and if they don't know they will ask sometimes an inappropriate question but — they want to learn so ... that's good.

\section{Aboriginal Law Centre ${ }^{19}$}

Part of the positive atmosphere within UNSW Law School came from a belief that it takes Indigenous issues seriously. Having the Aboriginal Law Centre at UNSW gave a good feeling about the Law School, and was seen as an indicator that the School is interested in and willing to act to benefit Indigenous people: ${ }^{20}$

That's the only Aboriginal Law Bulletin in Australia, so it was pretty good having that connected with my university.
A: I went (to Aboriginal Law Centre) ... and did some work there ...
Q: $\quad$ Did that help you in terms of getting involved in the Law School?

A: Yes, it did. To realise that the only Aboriginal Law Bulletin, or one of the major ones, is produced from the University of New South Wales, it just - they seem to have Aboriginal issues always to the fore at the University of New South Wales.

... Good in that the Law School is probably a little bit more progressive thinking than other places, and that people have access to that type of information, as well, and that they value Indigenous viewpoints within those bulletins.

It's really encouraging, ... gives you something to ... strive for, fight for ... it's good. It keeps us ... riled up, ready to go.

Clearly the focus on Indigenous issues adds a great deal of encouragement to students. The very existence of the Aboriginal Law Centre was seen by students as indicative of the importance with which Indigenous issues are treated. 


\section{Curriculum}

\section{General}

The National Aboriginal and Torres Strait Islander Education Policy states that "Aboriginal youth are more likely to participate in education ... when the curriculum is, and is perceived to be, relevant and appropriate." 21 The Law School at UNSW has made a great effort to provide such a curriculum. It first introduced a course on Aborigines and the law as long ago as 1979. Legal issues relating to Indigenous rights are incorporated into many compulsory subjects, and the establishment of the Aboriginal Law Centre and publication of the Aboriginal Law Bulletin add relevance. Students clearly felt that the inclusion of Indigenous issues in the curriculum assisted them to complete their studies:

As an Indigenous person if you're in a classroom learning about how the law affects your people, even if it's only for a class or two, it just makes the rest of it seem worthwhile

... I've got my part in here that I can relate to, and I can see how that fits in with the rest of the law and therefore, whilst I find this most important, it also makes you realise you have to learn the rest of it to be able to do something about it.

... Just an Aboriginal component to each subject at least for one class out of the session, just so that if you are an Indigenous student in that class, it's going to be like "wow, these people actually take an interest in my side of things." Any blackfella that's at Uni knows it's a white institution, and he just has to lump that, but at least if you're there and you know that the teachers have a good attitude towards Indigenous people, the teachers know what the general yarn is, you don’t have to be sitting there explaining to them where you're coming from ..

I did Admin Law and that was a compulsory subject, but for my major paper I wrote on access by Aboriginal and Torres Strait Islander people to Admin Law. That made it more interesting for me, it was more relevant than doing the sort of law that is compulsory. Students see the inclusion of material relating to Indigenous issues is relevant not only to them:

Aborigines and the Law, they don't offer that enough ... I'm thinking from another point of view, I think you might get more whites doing it, and I think it can only help, right? Whereas if they are only limited to the choice every second year and they've got to choose between that and something else ... I see education of whites being important.

[teaching Mambo and Aboriginal issues] ... widens the perspective of all students here, having those sort of things taught.

While the inclusion of Indigenous issues in the curriculum was viewed as a very positive contributor to Indigenous student success, this had both positive and negative impact for some students. Firstly students felt pressure to be expert on Indigenous issues, pressured to correct the teacher's or class's misunderstandings, and felt unable to distance themselves from the topics being studied:

There was one incident I remember, doing first year Torts, and having done Aboriginals and the law and whose possession and the whole bit and there was an article (the teacher) was reading and it just hit home and she hadn't realised that there was a Koori in the class and (I felt) "Oh, I've got to get out here, I've heard this before and I really don't want to hear it because it's happened before.” And then to go back into the discussion and hear all the guys going "oh yes, but this doesn't really happen now ..." and I'm "hold on, where have you been, kid? It's still happening and we're still fighting."

Anything Aboriginal ... you're supposed to really know.

Sensitive situations will arise, like I'm going to do Criminal Law next year and you can bet that there are going to be some black issues coming out of that and I think that will be very emotionally draining ... Even just having to go into the classes as a black woman, and having to sit through those sorts of discussions regardless of what the topic is I usually find quite difficult, and there are only one or two blacks there ...

... When those issues came up the class pretty much focused on you and on your point of view ...

Secondly, students felt that while teachers put Indigenous issues in a positive light, some teachers presented the material superficially:

When it comes to Indigenous issues a lot of the lecturers tend not to spend a lot of time on them ... especially in the Property courses where the land is of significance to Indigenous people.

But from hearing lecturers and watching their mannerisms it appears that they are ... they're uncomfortable with the 
idea of bringing the issues forward during their lectures ... and having the students address them.

I would kind of prefer ... something that's maybe taken outside the "poor old blackfella" type of feel, which is the way it's described in (named subject) ... And that kind of includes a whole lot of other areas of law as well. People think "Aborigines and the Law" and they think community legal centers and legal services, and that's the type of people that go and do the course. And I've noticed, especially in Property this year, that there's a real lack of understanding about what the broader issues are, and that people haven't made attempts ... I actually don't think a lot of the lecturers have made an attempt to go beyond what is kind of the warm and fuzzy feel about teaching (about Aborigines and the law).

While it is very important that teachers address these criticisms, it must be remembered that the inclusion of this material was overwhelmingly seen as positive. However, teachers raising Indigenous issues in their classes should be aware of the impact that this may have on Indigenous students, and remember also that the teacher is seen by other students as an authoritative voice. The way the teacher deals with the topic may therefore have a major impact in shaping the attitudes of other students in the class. If Indigenous issues are treated as unimportant or dealt with only superficially this may influence the degree of importance placed on those issues by other students.

The introduction of Indigenous material or perspectives to a law school curriculum does assist Indigenous students, but should be done respectfully and with care. Consultation could be carried out and the advice of appropriate Indigenous people or groups could be sought by curriculum review committees, or by teachers seeking to incorporate Indigenous issues into classes or materials.

It is important also to recognise the changes occurring in the Indigenous community, and to be aware of the diverse backgrounds of Indigenous students. What is relevant and appropriate may change over time, and it should not be assumed that everything dealing with 'Indigenous issues' will be relevant or appropriate as part of the curriculum.

\section{Classes and Teaching}

Although students were asked what style of teaching they preferred, and what made a teacher a good teacher, no common thread was found amongst responses. Most students believed that teaching style and method were a matter of personal preference only, and that these were far less important than a teacher's attitude and behaviour toward students.

However, difficulties with note-taking and organising material in discussion classes or seminars were mentioned commonly by students. Some felt confused with conversation coming from all parts of the classroom, and were left unsure of what was 'right' or what the point of the class was. Student comments suggest a lack of confidence and a consequent reliance on teachers to pull together the 'important' parts of the discussion. Discomfort with the language used in classes and less advanced academic skills may both contribute to the students' difficulty.

It is necessary that teachers make clear to students the major points or objectives of a class, and teachers running discussion classes may work with Indigenous students to ensure that they become comfortable with this class style and are not disadvantaged by it. Many students enjoyed the discussion classes despite finding them difficult academically and ending up 'without notes'.

\section{Student Support Scheme}

Support schemes for Indigenous students may contribute greatly to successful completion of degrees and lend weight to the students' belief in a school's general supportiveness. While the initial focus of the UNSW scheme was the provision of academic support through individual and small group tutorials, students claim that the benefits of such a program are far wider. ${ }^{23}$ The scheme now also offers personal and social support, and provides a link between Indigenous students and the Faculty. The scheme can also help build up student confidence:

Particularly in my first couple of years (the advisers) were extremely important. I remember my first day at this university, if (the adviser) hadn't been here that day I would have packed my bags and gone home.... Without that program I don’t think I would have got to where I am in my law degree.

Whenever I've had any problems or some intimidating assignments coming up or something like that, it's been less stressful because I know there's someone I can talk to. That's just so reassuring. 
... I can say that having (the adviser) there is a big help just to get your motivation, to keep you going, she'll say, "look, that's good, but keep going."

Students see the adviser as providing a link between themselves and the Law School. Some feel more part of the Law School because the adviser is there; others use the adviser for specific mediation and negotiation tasks. Both roles are seen by students as important contributors to their continued progress:

It's just good to have someone there ... Like you're not just a voice in the wilderness, just like on your own. There's some sort of a tie in with the Law School, so it's cool.

... It's a unique position and ... it's very valuable because sometimes it can be like "us" and "them”.

... Ultimately, we're going to need people to negotiate for us, because (the lecturers have) their little bag of rules that they've got to go by and that bag of rules includes details. And it's only because (the adviser's) negotiated enough trust that they'll take her word when she says “Take my word for it. They’ve got a reason.” ... I think the difference is, she knows the words they're looking for. We don't know what their little rules are. (The adviser) knows. She knows how to word it without telling our business.

The adviser also provides a channel for dealing with Indigenous student’s complaints:

... Also when things aren't going that well in the Law School, (the adviser's) the first point of contact in that sense, just to say "look, I don't really like this teacher”, or “I think this teacher doesn't like me,” or "I think I'm being picked on" or whatever it is. If you've got a gripe against any of the staff you know that (the adviser's) the one to go and see to say "What can I do, or what can you do?"

Unfortunately, taking advantage of the presence of the adviser places added burdens on students. Some students who feel the need for tutoring are simply unable to fit it into already crowded days:

I haven't had tutoring this session, and I could've used ... tutoring ... but my main problem is I don't have the time to do it, I don't actually have the time ever to get tutoring.

Various possibilities have been canvassed both at UNSW and at other universities regarding the possibility of providing appropriate support to Indigenous students without over-burdening them. The suggested solutions have included an extended first year which students have 18 months to complete, and which builds in additional tutorial support; a pre-law program to give an intensive preparation prior to commencing mainstream studies; flexible course structures which allow students to take less than a normal full academic load; and giving credit to Indigenous students for participation and success in parallel or additional classes, which may then take the place of a later year elective unit.

Options which have been introduced at UNSW are a flexible course structure and a pre-law program. Unfortunately, while the Law Faculty has been flexible in allowing Indigenous students to structure courses to meet their needs, there are other difficulties in this area. Abstudy, cadetships and professional study awards often require students to be enrolled in a full or near to full load. As a result students may need to enrol in more courses than they can comfortably carry, and forego additional support and tutorials. Other students enrol in extra subjects to receive their benefits and then withdraw at the last minute, leaving them with HECS liabilities and the pressure of incomplete or failed subjects on their academic transcripts. The adviser has frequently negotiated on behalf of students directly with government departments on the basis that attendance at additional tutorials means the student is in fact carrying a full load. Although these negotiations are often successful on an ad hoc basis, direct negotiation with government is likely to be the only way to overcome these difficulties. This rigidity of Abstudy rules is the subject of criticism by Aboriginal bodies. ${ }^{24}$

The other option introduced in an attempt to assist students without overburdening them is the Indigenous Pre- Law Program. This was introduced to UNSW in 1995 and repeated in 1996. The program aimed to give students an intensive preparatory law course, introducing them to academic expectations and skills, substantive law, university life, and support systems available to them. It included social and cultural sessions to assist students to develop support networks and coping strategies, and tried to give students an appreciation of what law study is like. While it was seen as a successful course by both students and teachers, it is unlikely that this will greatly reduce the need for additional support during law studies, given the breadth of the needs of Indigenous students at university. 


\section{ATAS - The Aboriginal Tutorial Assistance Scheme}

The Aboriginal Tutorial Assistance Scheme (ATAS), administered by the Department of Employment, Education and Training, contributes greatly to students completing their law degrees. ${ }^{25}$ As with the adviser in the Law School, ATAS tutors are used for far more than strictly academic tutorials. It is clear that the academic and personal aspects of the ATAS tutoring scheme are intertwined, and that the ability to tailor tutorial programs to individual needs is also vitally important:

I'd go and discuss it with my tutor and say "what they really want me to understand from this is X." And they would say "yes”, or they would say "yes, but ...” or they would say "Have you thought about this idea?" ... and it was just really good for me to get somebody listening on a personal level, and to just say "yes, you're right", and you really felt really good when you got that. They wouldn't give you a big pat on the head, they'd say "yeah, that's okay”, and even that was good. Just to know that you're on the right track.

Sometimes we may not talk about work but how I feel and how I'm coping with things and that's why my tutors have been good. So I can bounce ideas off ...

She was really good. And she kind of fitted in. She was happy not to have to see me regularly, so that wasn't a problem but she'd spend an entire four hours on Saturday afternoon or something with me, in the library going through stuff. And she was really, really good. And it was a big help.

I can sit there and read and it'll come into my head but to write it down I get a writer's block and I can sit there and argue a point face to face reasonably well, but I can't write it so ... it's a skill that needs to be done and that's what we've worked on this year for me, my tutors.

Students take advantage of the experience which their tutors have previously had in the Law School. As discussed above, this is of particular importance for Indigenous students who are unlikely to have relatives who have studied law, and the small number of Indigenous law students at university may make it difficult to find people familiar with the subjects they have chosen:

These tutors have done the courses before, they tend to know what different lecturers like, and the perspectives that different lecturers like people to take, so they can fill you in on those areas as well, they'd say "oh, no, this lecturer really likes this topic ..." So it's good for that sort of thing too, just to get the insight, past experience ...

While recognising the help that tutors can give, many students are keen to rely on themselves as far as possible, and to seek ATAS assistance only as a last resort:

I can appreciate that some people are not that confident in doing some work ... But then, by the same token, I think that the fact that there's this program available can be abused. The fact that people have a tutor just for the sake of having a tutor. And I feel as though ... first and foremost I should be the one to be able to do the work and then if I am having any problems, go and see (the adviser). If I'm having any further problems, then maybe a tutor then, but just because it's there, doesn't mean that I have to use it.

I remember when I got the first assignment the first thing I wanted to do was get a tutor straight away. Because I needed help I was just going berserk, but (the adviser) sort of said “you don't need a tutor, you can just work through it”. Thank God I did, because from that I sort of got more confidence and it was great — it was good after that.

Some students mentioned the initial difficulty of asking for ATAS tutoring, and the feelings which seeking extra tutoring may cause:

Oh, my God, I'm going to be so dumb, these tutors they're just going to laugh at me ... it was daunting going to see them ... And it was a bit scary to go and meet them and then you'd see them ... around the Law Faculty ... and you'd wonder how to react to them, but they just came up “Oh, hi, how are you?”

Some tutors received high praise and were recognised as contributing to the student's progress:

Q: $\quad$ So what makes a good tutor?

A: $\quad$ Somebody that's going to be critical, saying, “no, I don't think you've done this right. Go back and do it again", etc. Or "You should have looked at it from this point of view" or "what about these ..." Not all of them do that, they just look at it and say "yeah. Fix your spelling up."

While many students have obviously been helped to progress in their courses through the use of ATAS tutors, students have also criticised some tutors, the way some students use tutors, and the administration of the scheme. Even students who found the use of tutors beneficial found inconsistency in standard. Some tutors were vague, ill-prepared, willing to do student work, and more interested in the money than in the 
student or the ATAS Scheme. Some students also became totally dependent on tutors.

These criticisms are linked. By the time students enter university they may have had tutoring for many years, the ATAS scheme being available from kindergarten level right through to doctorate. While the student may have come to rely on the tutor, the tutor may also have come to rely on the student as a source of steady income. DEET staff administering the ATAS scheme are not qualified to check that work programs identify student needs or plan appropriate strategies for meeting these needs, nor to ensure that these plans are ever carried out. ${ }^{26}$ University staff coordinating the scheme are better qualified to do this, but rarely have the time for anything but the most minimal supervision. Further, university staff may come into conflict with students if they interfere, which can then disturb the student/adviser relationship. Students often also feel that ATAS tutoring is their entitlement, and so long as the necessary forms are correctly filled in DEET staff themselves assume the student and tutor are using the scheme appropriately. Some tutors play on this and continue with students well after any real need has passed.

Possible solutions include closer supervision and more thorough checking on tutorial programs, but the question of resources remains. While DEET has now begun passing the administration of the scheme to individual institutions, those institutions are not in a good position to improve it.

Workshops for ATAS tutors have been introduced at UNSW to try to overcome some of the difficulties. They inform tutors of their responsibilities, as well as offering a brief session on tutoring techniques. About sixty tutors from a number of disciplines have attended these workshops so far, and responses have been enthusiastic. They are now working more with staff of the Aboriginal Education Program, and toward the same ends. DEET has agreed to pay for tutors to attend these workshops.

While this has made a difference to the use of the ATAS scheme, there is still a great way to go before it can be said to be entirely beneficial. It is currently of great assistance to some students; but little use or even a hindrance to others.

\section{Cadetships, Traineeships, and Professional Study Awards}

Many government departments offer cadetships and traineeships to Indigenous students, who are paid while studying and work within the department during the summer break. Some departments offer professional study awards, whereby employees are given generous relief from duties to enable full time studies. UNSW itself offers a Careers Scheme Award similar to these, and supports some Indigenous students through their studies, giving them employment and training in the summer vacation. Cadetships, scholarships and traineeships are sought after by Indigenous students, who recognise that the schemes can change the situation for Indigenous people generally, as well as assisting individual students:

If nothing else, it allows (Indigenous students) to survive a little bit better, perhaps ease the potential drop-out rates ... and it also allows Aboriginal people ... to get into the senior professional positions, in equal competition with other cultures in Australia, which ... may not have been available until the last few years. If you're Aboriginal, you couldn't be trusted, you were illiterate, you were unintelligent, you were dirty ...

One of the things to work for next year is to try and get a cadetship. To me it's ... like a light at the end of the tunnel — it's something that I can strive for — I want to do well to try to get a cadetship.... it's ... something, when you're finding it all hard and that, it's something to look forward to.

Lack of financial support has always been recognised as a factor inhibiting Indigenous students from succeeding in education, and this is no different for law students. ${ }^{27}$ The financial aspects of cadetships and scholarships are therefore extremely important:

A lot of pressure off... . I'm not worrying about having to go out and work, and I'm not having to worry about a HECS bill that I can’t jump over once I graduate ...

Foremost is the financial support.... Abstudy is just not enough to survive on. I live out in the western suburbs so it takes me about two and a half hours to get to Uni. So, that money is going to be ... handy in the future because then I can move out. By the time I get home, it's two and a half hours later than I finish Uni. I'm stuffed, I don't want to do anything. And I probably could see that my work has been affected in that way in the past. So having this cadetship, and having that financial security, I may be able to move out of home and comfortably live.

The benefit of getting a cadetship would be firstly ... you get money, which is a very important thing, because I've known some of the students have just given up and been just flat broke, and they're just struggling, and if you're struggling to try and make ends meet, just eat and pay the bus fare to get out of here, let alone the rent - rent 
somewhere that's a lot closer ... so that they don't find it such a hassle, it's just ... some of that's just too much, and I've known some of the students that have dropped out ...

Another important aspect of the availability of cadetships and scholarships is the personal support and encouragement students may get. It is unfortunate that this kind of support' is lacking in some cadetships, as student comments clearly illustrate how helpful it can be when it is there:

They'll also support you while you're here, they ring you up sometimes and ask how you're going with your uni and ... Your personal support, it’s absolutely fantastic.

The mentor there, who I chose ... was very supportive. Every three or four weeks I get a phone call from her, just saying "Is it okay? How’s everything going?”

... They've supposedly got a person, ... that we're supposed to ring up if we're in trouble or we need support but the reality is there's one person to cover the whole of Australia. And they administer the whole section of scholarships and you can't get hold of them, so it's a waste of time.

As well as offering financial and sometimes personal support, many students feel that the cadetships contribute to successfully completing their degrees by exposing them to the work place, and giving them experience which can then be applied directly to their studies:

I had a placement with (government department) last summer, and the experience I got there has helped me so much this year. I'd only done one year of law and they were asking me to do things that I hadn't even heard of! I got the experience of being able to go to the library, research that, and then get a knowledge of that and then be able to carry out the work for them. So the experience has given me an advantage.

That has helped me a lot, knowing how to be really direct, and use the application of the law. ...It's one thing to learn it, and it's another to know how it's applied, and the difference between practice and theory, it's helped me a lot. And also, amazingly, it was the first time I ever saw things like statements of claims, and the actual practicalities of it, like advices and knowing how I'm going to use it all after I finish. I've brought that back to my study so I set out my papers like I would if I was a professional, or how they do as professionals ...

One factor which has been said to inhibit Indigenous students is a lack of motivation caused by an inability to see the long term benefits of their studies. The lack of role models almost certainly contributes to that. Cadetships however are acknowledged by students as helping them to gain that longer term focus:

Oh, it motivated me, that's for sure. It sort of gave me something to work for, because when I started my law degree, I really wanted to study law, but I didn't then and I still don't have any desire to ever be a lawyer. So when I started I knew the sort of areas that I was interested in but I didn't know quite what I was going to do with them, I didn't know how I was going to put it into practice at the end of my degree, so by working at the Commission I saw that I would be able to use my law degree.

If you know the area of work that you want to go into, then they're valuable.... even if you don't know, it gives you an opportunity to at least start to eliminate.

Students also recognise that cadetships will help them in future employment, both in gaining jobs and in performing once they are in them:

The work experience aspect is important, because when you graduate a lot of employers - they're looking for someone with a degree but they're also looking for someone with experience, someone who's mature and — I think that's where this cadetship comes into play.

If you were to ask me what would be better, the work experience or the money, I would go for the work experience, hands down. Because it gave me an edge and I don't think I'd be where I am today if I didn't go for that cadetship. Because I was able to work, and - first of all when you get out there and you go into the work force you think that you're going to get everything delivered on a platter and you're going to be making the decisions and high flying and this taught me a definite work structure, and ... just go and do the photocopying, go and do the filing, and you're right down the very bottom, so now that I'm a little bit higher up and I can really know personally how it feels to be that low and receive all the orders, and I think that's very important if you want to be anywhere in management, and just gives you personal skills and also the work skills, and also the experience. Like I wouldn't have received the job I have today if I had not been working where I got the cadetship.

Unfortunately some students reported many administrative difficulties with their cadetships and scholarships, but the effort students themselves put in evidences the importance they place on these schemes:

(I) actually negotiated my own cadetship. It was just such a nightmare I couldn't believe it. And I have to negotiate my own position when I get back. And I just, I didn’t have any energy left to continue to fight basically, so I just 
said, “oh, look, just give it to me. I don’t care.” I really needed money desperately. At this point I don’t have a mentor and I'm supposed to start work in a week's time. That's just ludicrous, isn't it? And because I haven't rung to say “Hey, who's going to be my mentor?” or nominate a mentor for myself, they haven't done that. I suspect that's because they have absolutely no ideas what their responsibilities are.

Some of the students feel the weight of stereotypes and tokenism in the administration of cadetships and scholarships. They were keen however to fight for change:

One of the gripes I have about being an Aboriginal student at uni doing a law degree is that ... being fair like I am, I get quite frustrated sometimes because I've been for a number of jobs, and there's always some reason why you don't get them and from experience, looking back at the people that do get them they always tend to be very stereotypically black, you know, they have black skin, they have frizzy hair, they have a broad nose, all the stereotypical things and the conclusion I've come to is that a lot of employers and people offering cadetships and traineeships want to have an identifiable black person, someone you can look at and within a split second you know that they're Aboriginal or Torres Strait Islander ... that's their token Indigenous person, basically. They don't want to have someone in that doesn't look Aboriginal ... And that gets a bit frustrating, when I know that I am Aboriginal and that I can do the job that's there, as well or better than the person they hired, and it's frustrating when you - all you can break it down to is that I don't look black enough for them. For them to consider me black. So that's frustrating.

I've heard recently that (named government department) says ...” oh, there's so many fair Aboriginals here" and they're going on about is it all worthwhile and that ... I think they try to intimidate you from going there. "They all just drop out anyway ... and stuff it, we'll tell the Government we tried but they (the Aboriginal cadets) won't do it”. But that sort of makes me more keen to go into it. Because you're changing the organisation, but also from there you've got access to a lot of networks and you can really change things.

While students find cadetships, traineeships, and professional study awards to be of great benefit there are clearly a number of issues in this area that still need to be addressed. Departments offering these schemes need to look closely at what they are trying to achieve and who they intend to benefit. If particular cadetships are taking off financial pressures but introducing others, it may be best that they are not offered. From student responses it can be seen that good models of practice do exist, and these should be examined by those departments not currently fulfilling their students' needs.

Because these schemes can be great contributors to student completion, it is worth ensuring that students are well advised in relation to them. Departments could be invited to make presentations and, as with other areas, the experiences of students who have taken part in these schemes would be invaluable. An information session would allow for these experiences to be passed on.

Further, while government departments have so far been most active, students are very interested in private firms offering these schemes. The NSW Law Society involved private firms in a special traineeship scheme in Law Week of 1993, the Year of Indigenous Peoples, which was well received by Indigenous students. Such initiatives should be further encouraged.

\section{Student Exchange Programs}

An exchange program running between the University of Alberta in Canada and the University of New South Wales allows Indigenous students from either university to study at the other, and to have their study credited to their home university. Although this exchange program has been taken up by only four law students, for those who have participated the opportunity greatly contributed to the completion of their studies:

Q: $\quad$ So what was it that stopped you from [dropping out]?

A: $\quad$... The Aboriginal Exchange to University of Alberta, because by the end of the third year, I was just sick of it. I was either going to have a year off, and then who knows what would have happened then, whether I'd have come back or not, but then that exchange came up and I went on that instead ...

... But last year, I got really sick of Sydney, I just couldn’t handle Sydney any more, that's why I went on the exchange ... I didn't want to lose any time off my degree, I wanted to keep studying but I just had to get out of Sydney.

Q: What are the things that ... stopped you from actually dropping out then?

A: I went to Canada on an exchange program. 
All students who went on the exchange program reported that it helped greatly with motivation as well as broadening their horizons generally. Because it is so beneficial such programs should be pursued further, and some form of financial assistance made available to help students to take advantage of this type of program.

\section{FURTHER CONTRIBUTORS TO SUCCESS}

The factors mentioned above are those most frequently mentioned by students, and most significant to those who benefited from them. If any of these factors were missing at least some students may not complete or have completed their law degrees. While acknowledging the many positive contributions already available students also made suggestions for further improvement.

Students commonly suggested that a great deal of crosscultural training was required within the University and the Law School. Responses suggested that the study experiences of Indigenous students would be much improved if teachers, administrators and other students had a better understanding of Aborigines and Tones Strait Islanders. Although they felt supported in their studies, they also believed there was a marked lack of knowledge of Indigenous history and culture:

The Law School is pretty much a reflection of our society. I think that a lot of people I know are unaware of Indigenous issues.

They should be ... told more about Aboriginal students and what background they are coming from... . Some of them are really hard to approach ... for normal students, ... for Aboriginal people it’s just hideous.

... Having some of the lecturers aware of Koori culture ... what we're all about. We are different from everybody else in the class ... in terms of our culture. And I guess, having cultural awareness workshops or something for the tutors and the lecturers ...

Students anticipated that the appointment of Indigenous people to the academic and administrative staff of the Law School and to the counselling section of the University would significantly contribute to the completion of degrees. Students want university staff who understand how they feel, and who share their experiences:

If you are having an Aboriginal lecturer it makes a world of difference. I know when we've had guest speakers come in and there's an Aboriginal person talking up the front, you relax straight away, you feel really good, you can identify with them. I think it would make a world of difference.

It was just like a Godsend when (Aboriginal lecturer) walked in, I just thought "I can't believe this, this session is going to pick up, it's going to be a better half of the year!” That was really, I don't know, it's just, more not feeling so isolated sometimes.

A Koori counselling service, because a lot of times there's a whole heap of personal problems that we have to deal with, that's a full range of problems ...

What also would be helpful is having a counsellor who is Aboriginal or Torres Strait Islander because at the moment there are none. I think we need that.

Cross-cultural training aimed specifically at making staff and students aware of Indigenous cultures may assist further. Much of the 'cross-cultural' activity within universities currently emphasises an understanding predominantly of Asian cultures, and Indigenous students would prefer a shift toward the inclusion of their cultures in such programs.

While current moves toward employing Indigenous academic staff fit well with student suggestions for positive change, responses indicate that the employment of Indigenous administrative staff is also very important. Further, training for all administrative staff which emphasises Indigenous culture is seen as crucial by students. For many students the lack of understanding of some administrative staff was a significant negative factor in their university experiences.

\section{CONCLUSION}

It is clear from student responses that student motivation is a major player in student success, and that that motivation can be bolstered through the encouragement of student networks, role modelling, a 
supportive law faculty, relevant and appropriate curricula, a far-reaching student support scheme, ATAS tutoring, cadetships and exchange programs. It is encouraging to learn that so many of these factors which contribute to Indigenous students succeeding in law studies can be influenced by those within the university.

This knowledge requires that those within the university accept responsibility for ensuring the establishment and maintenance of structures which support and encourage Indigenous students to complete their studies. These structural factors include such things as a centre for Indigenous students, special admissions schemes, support schemes within law schools, and relevant and appropriate curricula.

This structural support should not however overshadow the importance of personal support offered by individual staff and by staff as a whole. The impact of positive staff attitudes and behaviour was mentioned throughout the interviews, where even lecturing, tutoring and cadetships were often evaluated by respondents in terms of the personal encouragement and support they gave, rather than in terms of academic or financial assistance. It is necessary that teachers and other staff recognise that their behaviour can significantly influence an Indigenous student's chance of success.

It must be remembered also that the factors identified as contributing to students completing degrees are intertwined. Although these factors have been discussed individually, what in fact assists Indigenous law students is more than the sum of the numerous parts. Students are assisted rather by the far-reaching nature of the support and the fact that so many aspects of their study environment carry with them support and encouragement. Before introducing changes to any of these areas the possibility that that change will impact more broadly on the whole experience of Indigenous law students must be taken into account.

The focus on success does not reduce the need for understanding the complexity of the Indigenous student experience in law school. As many students still commence but do not complete degrees it is clear that significant barriers remain, and that further research in this field must be conducted. It is hoped however that the identification of positive contributors to success will allow universities and law schools to do more of what they are doing well, and to introduce further positive factors to the Indigenous law students' study environment.

* Lecturer, University of New South Wales Law School/Aboriginal Education Program. Thanks to all Indigenous law students at UNSW for their generosity of spirit, and to Anita Heiss whose sensitive interviewing captured this. (C) 1997. (1996) 7 Legal Educ Rev 155.

1 Australian Bureau of Statistics, Report on Australia's Aboriginal and Torres Strait Islander Population (Canberra: AGPS, 1993) Based on the 1991 census, the report states that approximately 7\% of Indigenous Australians aged 15 to 24 years attend tertiary institutions compared with nearly $25 \%$ of non-Indigenous Australians.

2 See for example C Spencer, First Year Students Face Unique Problems Campus Review: Indigenous Education Special 1-7 June 1995, at 12; DF Jordan, Support Systems for Aboriginal Students in Higher Education Institutions (Adelaide: Tertiary Education Authority of South Australia, 1985); J Gallagher, A Support System for Aboriginal Students in the University of New South Wales: Final Report to the Gange Bequest Committee (Held on file: Aboriginal Education Program UNSW, 1986).

3 Id.

4 “Indigenous” is used to refer to Australian Aborigines and Torres Strait Islanders. As it refers to a particular group of indigenous people, capitalization is appropriate.

5 A 1993 report stated that while Australia had about 20 Aboriginal law graduates, true representation on the basis of population would have required closer to 1200 such graduates. D’Lavery, The Participation of Indigenous Australians in Legal Education (1993) 4 Legal Educ Rev 177, at 180.

6 UNSW Law School had 11 Indigenous graduates prior to 1991 - more than half such graduates in Australia (Lavery, supra note 4) — and a further 12 students completed their degrees at UNSW in the four years to December 1995.

7 It is difficult to calculate attrition exactly as many Indigenous law students transfer between universities or return to study after extended absences. Even with this taken into account attrition remains a major concern. For example, of 24 new Indigenous students at UNSW Law School in the period 1992-1995 only 14 have graduated or remain enrolled, representing a retention rate of less than $60 \%$.

8 See for example E West, An Indigenous University for Australia? (1994) July/August NTEU Advoc 21; National Federation of Aboriginal Education Consultative Groups, National Review of Education for Aboriginal and Torres Strait Islander People: Response from the National Federation of AECGs (Canberra, AGPS, 1994).

9 For discussion on the use of qualitative analyses see: A Bryman, Quantity and Quality in Social Research (London: Routledge, 1988); CM Judd, ER Smith, \& LH Kidder, Research Methods in Social Relations 6th ed (Fort Worth: Holt, Rinehart \& Winston, 1991) ch 13.

10 Supra note 2.

11 Student words are reproduced as transcribed from tape, but with deletion in most instances of "um, er, like, you know, sort of". The retention of these fillers can make students appear far less articulate than they are, but the author has also been careful not to make student responses too definite by over-deletion.

12 Very similar difficulties were reported by Canadian Indigenous students, in some cases almost mirroring the words of Australian Indigenous students: see First Nations Law Students Association, Broadening the Law School Perspective: First Nations Law Students Curriculum Conference Report (Toronto: Osgoode Hall Law School, 1992). 
13 UNSW's Aboriginal Student Centre was established in 1987 to provide a permanent meeting place for Indigenous students, and to provide a definite Indigenous presence on campus. The Centre has a lounge room, kitchen, a number of computer terminals for student use, a small library, and a tutorial room. It has well used notice boards carrying information about Indigenous issues and events.

14 It has been suggested that in Canada Native students are sufficiently strong in their identity not to feel it at risk in non-Indigenous institutions; S Deloria, Legal Education and Native People (1974) 22 Sask L Rev 22, at 39. Contrast the strength of cultural background in Australia, where many Indigenous students have had little or no contact with Indigenous cultures.

15 If this is not done early the problem may be compounded. One student for example did not attend an introductory morning tea for new students as she was embarrassed she looked too fair. She would like to take part in the Aboriginal Education Program, but feels now that missing past events has exacerbated the difficulty of her situation. She is now worried not only by being fairskinned, but also by her lack of involvement in the program so far.

16 N Tomas, \& A Jones, Academic Achievement in an Alien Cultural Environment: The Maori Academic Program at the University of Auckland Faculty of Law (Unpublished: 1993).

17 University of New South Wales Faculty of Law, Corporate Plan 1996-2001 (Sydney: UNSW, 1995) 7.

18 Id at 4.

19 Now known as the Indigenous Law Centre.

20 The Aboriginal Law Centre located within UNSW Law School collects and houses material relating to these issues, publishes the Aboriginal Law Bulletin and Indigenous Law Reporter, and undertakes related projects and consultancies. Aboriginal Law Bulletin is now Indigenous Law Bulletin.

21 Commonwealth Department of Employment, Education and Training, National Aboriginal and Torres Strait Islander Education Policy (Canberra: AGPS, 1989) 13.

22 The Law Faculty support scheme for Indigenous students at UNSW was set up jointly by the Aboriginal Education Program and the Law School in 1989. The staff member responsible for the scheme is referred to here as 'adviser' to avoid confusion with mainstream teachers and ATAS tutors.

23 For more information on UNSW's student support program see C Penfold, Support for Indigenous Students in the Faculty of Law 1989-1995: Report to the Dean of Law. (Held on file, UNSW Faculty of Law, 1996.)

24 National Federation of Aboriginal Education Consultative Groups, National Review of Education for Aboriginal and Torres Strait Islander People: Response from the National Federation of AECGs (Canberra: AGPS 1994), 16.

25 DEET funds tutoring of up to two hours per week per subject for Indigenous tertiary students. At UNSW ATAS tutors are usually non-Indigenous law students in the later years of study, or graduates enrolled at the College of Law.

26 A DEET field officer told the adviser regarding the student application and the tutor work program: “So long as there’s something written there we don't actually read it. We'd only question it if it was left blank.”

27 Some Canadian literature in fact suggests that lack of finance is the most significant factor inhibiting Indigenous students from completing law degrees. Deloria, supra note 12, at 23. 